\title{
Rolling Characteristics in the Twin-Roll Rapid Solidification Process*
}

\author{
By Ken-ichi Miyazawa**†, Takao Choh** and Michio Inouye***
}

\begin{abstract}
The twin-roll rapid solidification process was investigated both experimentally and theoretically to explore rolling characteristics of the process.

Results of the experiment using a $\mathrm{Pb}-\mathrm{Sb}$ eutectic alloy show that the thickness of a rapidly solidified metallic ribbon decreases with increasing roll rotation speed and with decreasing initial roll gap and melt flow rate. The cross-sectional area of the ribbon is in proportion to the ratio of the melt flow rate to the roll rotation speed and does not depend on the initial roll gap.

Based on the reduction ratio in thickness of the solidified ribbon and the roll gap enlarged by a rolling load, effects of key process parameters on the ribbon geometry are discussed. The calculated roll separating force has been confirmed to agree well with the observed value.
\end{abstract}

(Received May 6, 1983)

\begin{abstract}
Keywords: rapid solidification, twin-roll process, melt rolling, rapidly solidified metallic ribbon, roll separating force, rolling theory, rolling deformation flow of metal, leadantimony eutectic alloy
\end{abstract}

\section{Introduction}

Recently there has been a growing interest in rapidly solidified metals, especially in amorphous metals. Ribbon-shaped metals are produced mainly by the chill block melt spinning process (single-roll method) or by the twin-roll method in which melt is directly rolled. Although a number of studies have been reported on properties of the metals, less information is available regarding transport phenomena taking place in the rapid solidification processes and the process operations.

The twin-roll process is one of the promising ways not only for the preparation of amorphous metallic ribbons but also for the practical production of silicon steel or sendust alloy sheets $^{(1)-(4)}$. Thus, also from the industrial

* This paper was originally published in Japanese in J. Japan Inst. Metals, 46 (1982), 944.

** Department of Metallurgical Engineering, Faculty of Engineering, Nagoya University, Nagoya 464, Japan.

$\dagger$ Present address: R. \& D. Laboratories-I,Nippon Steel Corporation, 1618 Ida, Nakahara-ku, Kawasaki 211, Japan.

*** Department of Metallurgical Engineering, Faculty of Engineering, Nagoya University, Nagoya 464, Japan. Now, Professor Emeritus of Nagoya University. point of view, it is of importance to understand characteristics of the process.

In this process, pouring melt into the gap between rotating rolls yields a solidified ribbon. The melt flow, the rapid solidification from roll surfaces and the deformation flow of metal solidified during the rolling simultaneously take place in the roll gap. Because of the complicated transport phenomena in the process, the mechanism controlling the geometry of metallic ribbons is not known yet. Therefore, in the present study, the experiment using a low melting temperature alloy was done to obtain fundamental data on the rolling characteristics in the process. On the basis of the experimental results and the theoretical analysis on the deformation flow of the metal solidified during the melt rolling, the rolling characteristics in the twin-roll process is investigated.

\section{II. .Experimental Procedure}

Figure 1 shows a schematic view of the twinroll process. $\mathrm{A} \mathrm{Pb}_{82.5} \mathrm{Sb}_{17.5}$ eutectic alloy (melting temperature $525 \mathrm{~K}$ ) in a round orifice nozzle of transparent quartz $(0.5 \mathrm{~mm} \phi)$ was melted by a resistance furnace and kept at a given temperature $(553 \mathrm{~K})$. The melt was ejected into the gap between rotating Cr-steel rolls ( $70 \mathrm{~mm}$ in diameter) by introducing Ar gas into the nozzle through a solenoid valve. 


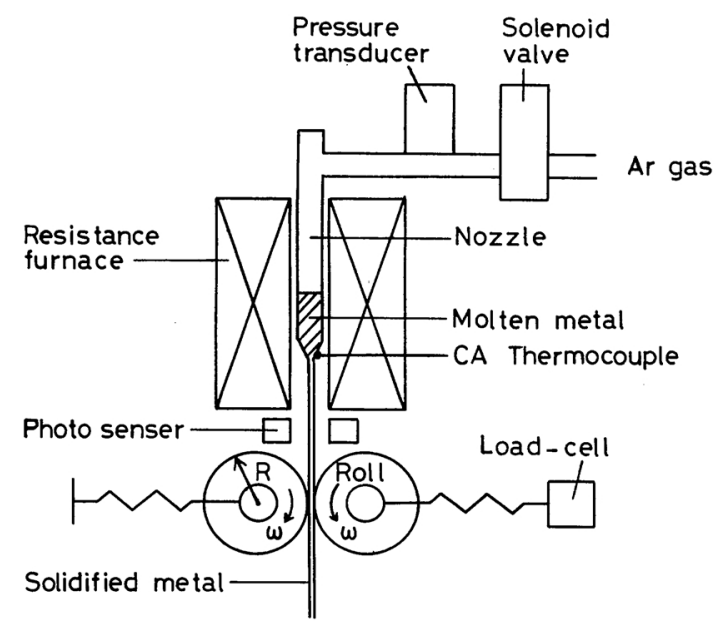

Fig. 1 Schematic view of the twin-roll rapid solidification process.

Table 1 Experimental conditions.

\begin{tabular}{|c|c|c|c|}
\hline Series No. & $\begin{array}{|cc|}\text { Roll rotation speed } \\
\omega_{0} & \mathrm{rpm}\left(\mathrm{s}^{-1}\right) \\
\end{array}$ & $\begin{array}{r}\text { Initial roll gap } \\
2 \mathrm{H}_{00}(\mu \mathrm{m})\end{array}$ & \begin{tabular}{|c}
$\begin{array}{c}\text { Ejection pressure } \\
\mathrm{P}_{\mathrm{N}} \quad(\mathrm{MPa})\end{array}$ \\
\end{tabular} \\
\hline E 1 & \multirow{2}{*}{$\begin{array}{l}280 \sim 2750 \\
(4.7 \sim 45.8)\end{array}$} & 60 & 0.033 \\
\hline E 2 & & 50 & 0.033 \\
\hline E 3 & \multirow{3}{*}{$\begin{array}{l}1250 \\
(20.8)\end{array}$} & $0 \sim 100$ & 0.060 \\
\hline E 4 & & 25 & $0.017 \sim 0.128$ \\
\hline E 5 & & 55 & $0.017 \sim 0.128$ \\
\hline
\end{tabular}

A series of experiments were done by systematically changing such key process parameters as roll rotation speed, initial roll gap and melt ejection pressure. The experimental conditions are listed in Table 1. The roll rotation speed and the roll gap were measured under unloading. During melt rolling, the roll separation force was measured by a load cell, the ejection pressure by a pressure transducer and the duration of melt pouring by a photo-senser.

\section{Experimental Results and Discussion}

Under the experimental conditions of a constant orifice diameter, a constant melt temperature and a small melt height in the nozzle, the melt flow rate at the nozzle outlet, $Q^{\prime}(\mathrm{g} / \mathrm{s})$, depends only on the ejection pressure, $P_{\mathrm{n}}(\mathrm{MPa})$. The relation experimentally obtained is expressed by $Q^{\prime}=11.2 \sqrt{P_{\mathrm{n}}}$ with accuracy of about $\pm 5 \%$, where $Q^{\prime}$ is the amount of ribbon weight divided by the pouring duration of melt. Thus, in this paper, experimental results are discussed by the use of the melt flow rate instead of the ejection pressure.

In the experiments, metallic ribbons 2.5$15 \mathrm{~m}$ in length were made from the melt of 3-5 $\mathrm{g}$ per run without break. The results of measurements of the ribbon dimensions revealed the thickness and width to periodically change in the casting direction. A typical example observed in the central part of ribbon is shown in Fig. 2. Since the periods of the changes closely agree with the circumference of rolls used, the eccentricity of the rolls may be presumed to result in the periodic changes. It is to be noted that the periodic changes in ribbon geometry due to the eccentricity of rolls are invisible to the naked eye, because the amplitudes are much smaller than the periods.

However, change in the ribbon width like a bamboo joint was detected by the naked eye under a low roll rotation speed. This change in width appears at nearly regular intervals in the casting direction. In the experiments $\mathrm{E} 1$ and $\mathrm{E} 2$, the interval reduced from 10 to $4 \mathrm{~mm}$ with increasing roll rotation speed from $280 \mathrm{rpm}$ $\left(4.7 \mathrm{~s}^{-1}\right)$ to $1000 \mathrm{rpm}\left(16.7 \mathrm{~s}^{-1}\right)$, and the change in width did not occur for the higher roll rotation speeds than $1250 \mathrm{rpm}\left(20.8 \mathrm{~s}^{-1}\right)$. The occurrence would depend on vibration of the melt jet flowing out of the nozzle and on that of the melt puddle in the gap between rolls.

Recently, Ishihara and Ikuta ${ }^{(5)}$ have reported that in the case of a round orifice nozzle the thickness of Co alloy ribbons is not uniform in the width-direction, smaller at both the ends and the center. On the other hand, the thickness of the ribbons produced in our experiments was

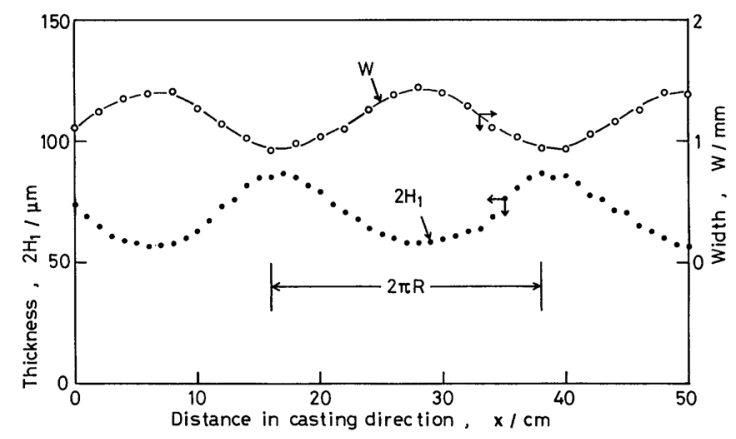

Fig. 2 Thickness and width of solidified metallic ribbon. $\left(\mathrm{E} 2, \omega_{0}=12.5 \mathrm{~s}^{-1}(750 \mathrm{rpm})\right)$ 
almost uniform in the width-direction. As the reason for the uniform ribbon thickness, it is considered that the melt superheat was small in our experiments, the $\mathrm{Pb}-\mathrm{Sb}$ eutectic alloy is softer than the roll material used and the ribbon width was relatively small.

As mentioned above, the ribbon geometry periodically changes in the casting direction. Thus, by using each mean value of the thickness and width, effects of the key process parameters on the ribbon geometry were examined. Figure 3 shows the effect of roll rotation speed on the ribbon thickness and width. It is seen that with increasing roll rotation speed $\left(\omega_{0}\right)$ both the thickness $\left(2 H_{1}\right)$ and the width $(W)$ decrease. The logarithmic plot of the experimental data reveales the relations of $2 \mathrm{H}_{1} \propto$ $\omega^{-0.2}$ and $W \propto \omega^{-0.8}$. The amplitude of the periodic change in the ribbon width in the casting direction is found to decrease with increasing roll rotation speed, while that of thickness is almost constant.

The mean ribbon thickness and width observed for various initial roll gaps are shown in Fig. 4. With increasing initial roll gap the width increases and correspondingly the thickness increases so as to approach the initial roll gap. Figure 4 shows that the thickness has the

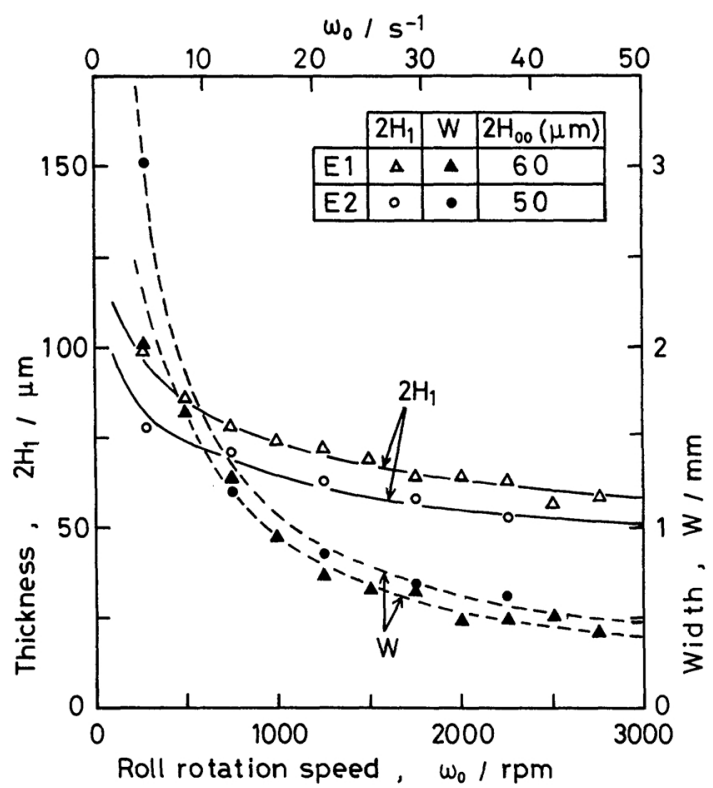

Fig. 3 Effects of roll rotation speed on ribbon thickness and width. (Average melt flow rate $\bar{Q}^{\prime}=2.0 \mathrm{~g} / \mathrm{s}$ )

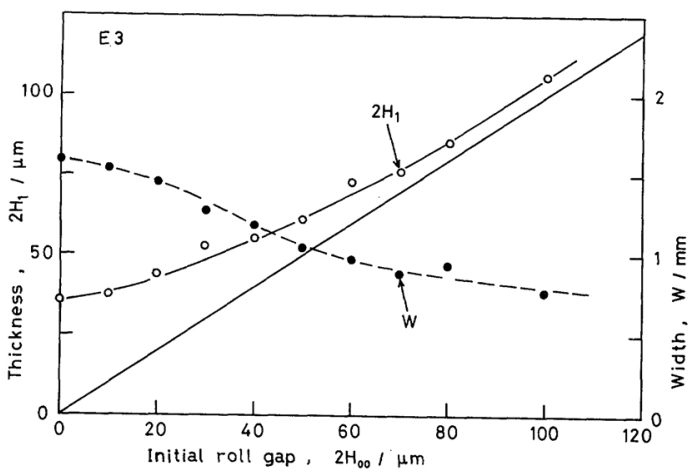

Fig. 4 Effects of initial roll gap on ribbon thickness and width. (Average melt flow rate $\bar{Q}^{\prime}=2.7 \mathrm{~g} / \mathrm{s}$ )

minimum at zero initial roll gap. The ribbon of finite thickness can be produced even if the initial roll gap is zero. This fact indicates that the roll gap is enlarged during the melt rolling by the load.

Figure 5 shows the effect of melt flow rate on the ribbon geometry. It is seen that the ribbon width linearly increases with increasing melt flow rate, while the change in thickness is relatively small.

Figure 6 shows the relation between the crosssectional area of ribbon and the key process parameters. The cross-sectional area is proportional to the ratio of the melt flow rate to the roll rotation speed and does not depend on the initial roll gap. The empirical equation written in Fig. 6 approximately agrees with the mass balance at the location where the solidified metal departs from the rolls (eq. (8)).

The rolling speed of solidified ribbon obtained by dividing the ribbon length by the

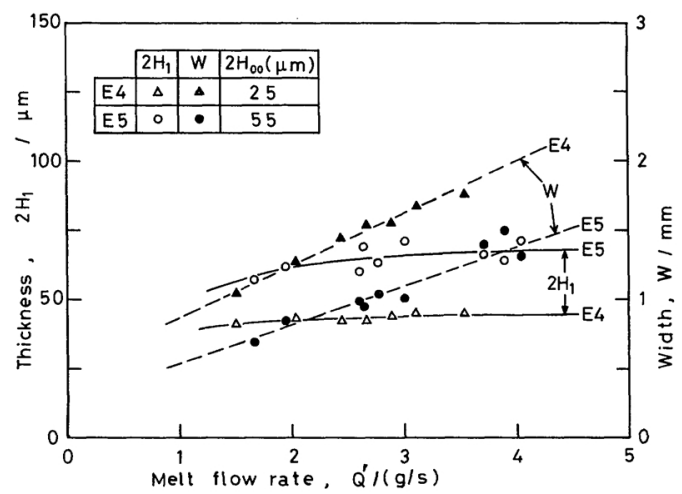

Fig. 5 Effects of melt flow rate on ribbon thickness and width. 


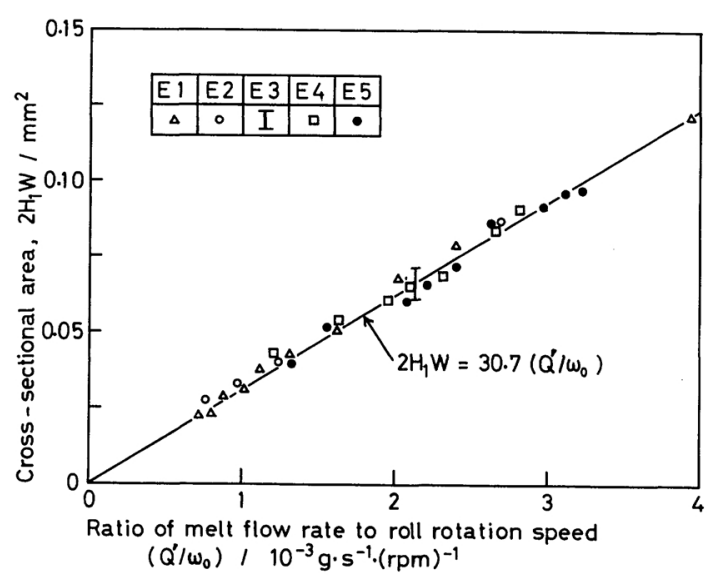

Fig. 6 Relationship between observed cross-sectional area of ribbon and the ratio of melt flow rate to roll rotation speed.

pouring duration of melt is plotted in Fig. 7. The rolling speed is proportional to the roll rotation speed under unloading. However, it is about $15 \%$ smaller than the tangential component of roll surface velocity under unloading $\left(V_{0}\right)$. This should be the result of the slip between the roll surfaces and the solidified ribbon,

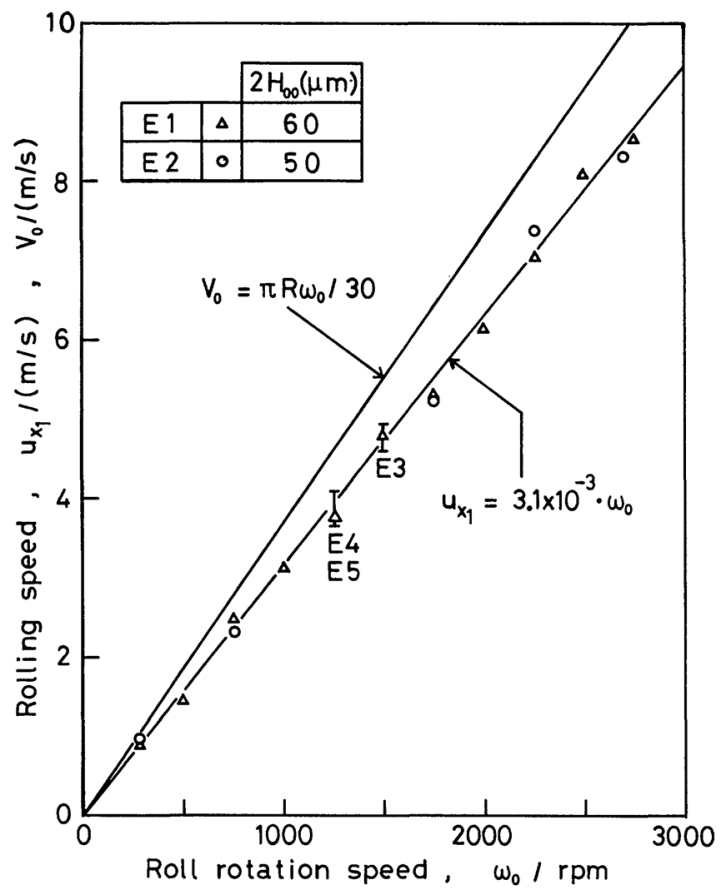

Fig. 7 Comparison between rolling speed of ribbon and roll surface velocity under unloading $\left(V_{0}\right)$. since the observed decrease in the roll rotation speed due to the rolling load was very small.

The melt flowing out of a round orifice nozzle spreads in the direction of roll axis. For a constant roll gap, the amount of the melt spreading is determined by the balance of the melt flow rate with the rolling speed of solidified ribbon. As it is seen from Fig. 7, the rolling speed of ribbon increases with increasing roll rotation speed. This makes both the accumulation and the spreading of melt in the roll gap decrease. Consequently the ribbon width decreases with increasing roll rotation speed, as shown in Fig. 3. From the results of Fig. 5 where the rolling speed of solidified metal was kept constant, the melt spreading can be inferred to increase with increasing melt flow rate. The flow rate of solidified metal per unit width increases with increasing initial roll gap, although the rolling speed is kept constant. Thus, the melt spreading in the direction of roll axis decreases with increasing initial roll gap, and consequently the ribbon width decreases, as shown in Fig. 4.

It is important to know the ribbon length per unit mass, $l(\mathrm{~m} / \mathrm{kg})$, for the practical production of rapidly solidified ribbons. From the data obtained in this study, it has been found that $l$ is proportional exclusively to the ratio of the roll surface velocity, $V_{0}(\mathrm{~m} / \mathrm{s})$, to the melt flow rate, $Q^{\prime}(\mathrm{kg} / \mathrm{s})$, as follows;

$$
l=0.846 V_{0} / Q^{\prime} .
$$

The observed relations between the roll separating force $\left(F_{s}^{\prime}\right)$ and the key process parameters are shown in Figs. 8-10. It is seen in Figs. 8 and 9 that the roll separating force decreases with increasing roll rotation speed and initial roll gap. Figure 10 indicates the roll separating force to increase almost linearly with increasing melt flow rate. The roll separating force per unit width $\left(F_{\mathrm{s}}\right)$ shown in Figs. $8-10$ is important for determining the force necessary to support rolls, especially in the production of wider ribbons using multiple-orifice or slit-type nozzles. The dependence of $F_{\mathrm{s}}$ on the key process parameters is the same as that of $F_{s}^{\prime}$, although the changes in $F_{\mathrm{s}}$ with the parameters are smaller than those of $F_{\mathrm{s}}^{\prime}$. As known from the comparisons of the ribbon thickness in Figs. 


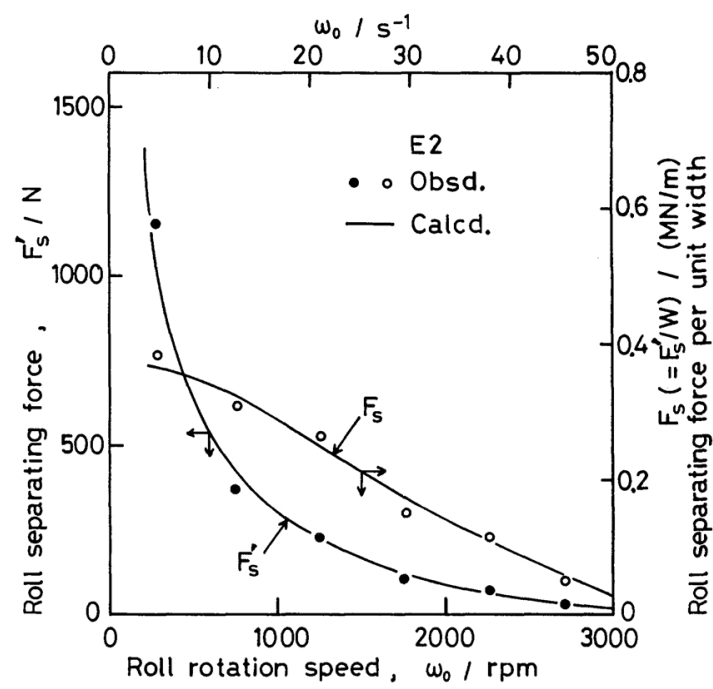

Fig. 8 Effects of roll rotation speed on roll separating forces.

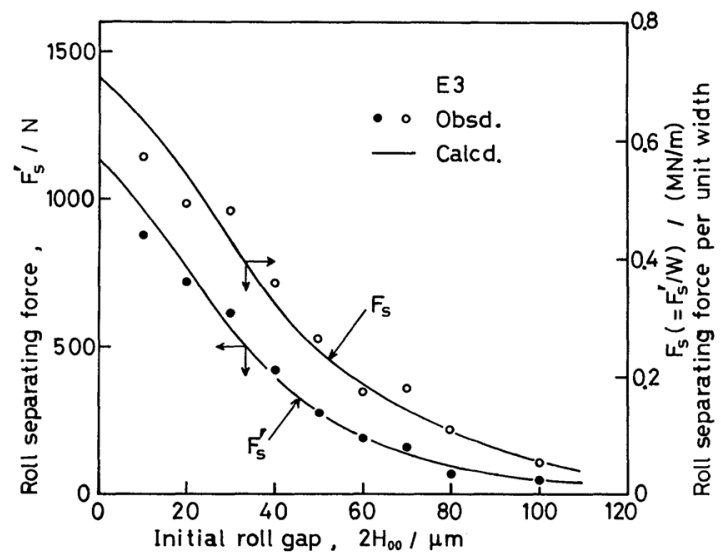

Fig. 9 Effects of initial roll gap on roll separating forces.

3-5 with the roll separating force in Figs. 8-10, the difference between the ribbon thickness and the initial roll gap increases with increasing roll separating force. Thus, the roll separating force is one of the important variables to controll the ribbon thickness.

\section{Theoretical Analysis on Rolling of Solidified Metal}

In the experimental results mentioned above, the roll gap has been deduced to be enlarged during rolling. By further development of the

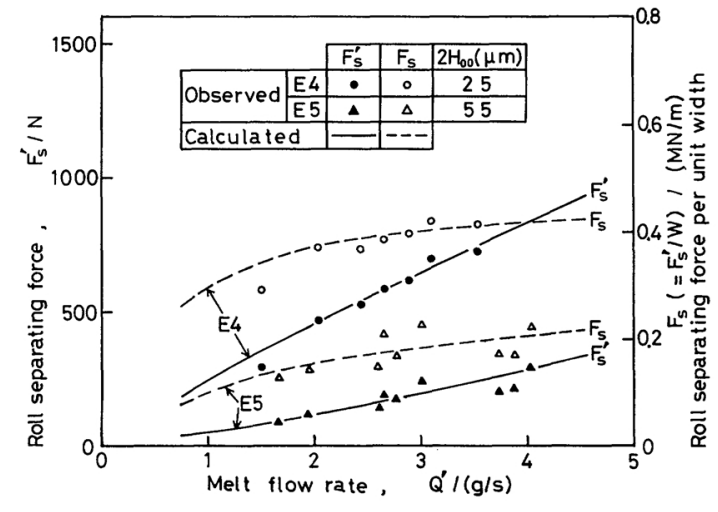

Fig. 10 Effects of melt flow rate on roll separating forces.

previously presented theoretical analysis ${ }^{(6)}$ on the deformation flow of metal solidified in the roll gap during rolling, the enlargement of roll gap caused by rolling load is estimated in the following.

As the resistance of melt to the rolling deformation is generally much smaller than that of solid, the roll gap during rolling in the twinroll process can be determined by a balance of the deformation resistance of solidified metal (rolling load) with the force to support two rolls. In the rolling machine used, springs were adopted to support the rolls. Thus, the relation between the roll separating force and the enlargement of roll gap can be expressed by Hooke's law, as follows;

$$
F_{s}^{\prime}=k_{\mathrm{sp}}\left(H_{0}-H_{00}\right) \text {, }
$$

where $H_{0}$ and $H_{00}$ are roll gaps during rolling and under unloading, respectively, and $k_{\mathrm{sp}}$ an apparent spring constant.

According to the previous mathematical model $^{(6)}$, when the constitutive equation for the deformation of solidified metal is expressed by eq. (3), the gradient of hydrostatic pressure in a solid region of roll gap is given by eq. (4) on the basis of the stress balance in the casting direction $(x)$, the equation of continuity and the overall mass balance in the gap between rolls.

$$
\dot{\varepsilon}=A \sigma^{m}
$$

and

$$
\frac{\mathrm{d} P_{\mathrm{s}}}{\mathrm{d} x}=\frac{1}{B H}\left(\frac{m+2}{H}\right)^{1 / m} \cdot\left|u_{\mathrm{x}}-C\right|^{1 / m-1} \cdot\left(u_{\mathrm{x}}-C\right),
$$


where $B=3^{(1+1 / m) / 2} \cdot A^{1 / m}, \quad C=Q^{\prime} / 2 \rho H W, \dot{\varepsilon}$ : strain rate, $\sigma$ : stress, $Q^{\prime}$ : mass flow rate, $\rho$ : density, $W$ : ribbon width. The half distance between rolls $(H)$ and the $x$-component of ribbon surface velocity $\left(u_{\mathrm{x}}\right)$ can be expressed by eqs. (5) and (6), respectively.

$$
H=H_{0}+R-\left(R^{2}-x^{2}\right)^{1 / 2}
$$

and

$$
u_{\mathrm{x}}=\beta\left(\pi R \omega_{0} / 30\right) \cdot\left(R^{2}-x^{2}\right)^{1 / 2} / R,
$$

where $R$ is a roll radius, $\omega_{0}$ a roll rotation speed under unloading and $\beta$ a slip factor introduced in the light of the observed rolling speed in Fig. 7.

Since the pressures in the melt and the meltsolid regions between rolls are much smaller than the hydrostatic pressure in the solid region, the following boundary conditions at the end point of solidification and at the outlet of solidified ribbon can be applied to eq. (4).

$$
P_{\mathrm{s}}=P_{\mathrm{s} 0} \text { at } x=-x_{2} \text { and } x=x_{1} .
$$

If $H_{0}$ and $x_{1}$ are known, $P_{\mathrm{s}}$ and $x_{2}$ can be calculated by integrating eq. (4) from $x=x_{1}$ to the negative direction of $x$. When no external force is applied to the solidified ribbon at the outlet, the $x$-component of metal velocity is uniformly distributed at the position and thus the mass balance is given by eq. (8).

$$
Q^{\prime}=2 \rho H_{1} W u_{\mathrm{x} 1} \text { at } x=x_{1} \text {. }
$$

From eqs. (5), (6) and (8), the relation between the roll gap during rolling $\left(H_{0}\right)$ and the outlet of ribbon $\left(x_{1}\right)$ is obtained as follows;

$$
\begin{aligned}
H_{0}+R= & \left(R^{2}-x_{1}^{2}\right)^{1 / 2} \\
& +15 Q^{\prime} / \beta \pi \rho \omega_{0} W\left(R^{2}-x_{1}^{2}\right)^{1 / 2} .
\end{aligned}
$$

The roll separating force is expressed by eq. (10).

$$
F_{s}^{\prime}=\int_{-x_{2}}^{x_{1}} W\left(P_{\mathrm{s}}-P_{\mathrm{s} 0}\right) \mathrm{d} x .
$$

The roll gap during rolling $\left(2 H_{0}\right)$, the roll separating force $\left(F_{\mathrm{s}}^{\prime}\right)$, the end point of solidification $\left(-x_{2}\right)$, the outlet of ribbon $\left(x_{1}\right)$ and the ribbon thickness $\left(2 \mathrm{H}_{1}\right)$ can be obtained from a trial and error calculation using eqs. (2), (4), (5)-(7), (9) and (10). A flow chart of the calculation is shown in Fig. 11. Runge-Kutta method was used for the numerical integration

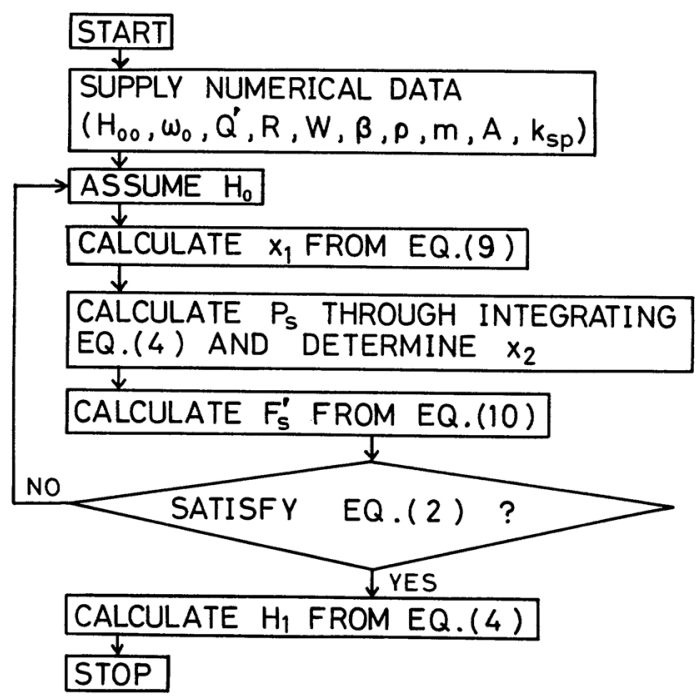

Fig. 11 Flow chart for computation.

of eq. (4).

\section{Calculated Results and Discussion}

Of numerical values necessary for the calculation in Fig. 11, the material properties ( $m$ and $A$ in eq. (3)) and the apparent spring constant $\left(k_{\mathrm{sp}}\right)$ are unknown. Thus, firstly, these values were sought by a trial and error procedure so that the calculated roll separating force agreed with the results observed in the experiment E2. The other necessary values used are $R=35 \times 10^{-3} \mathrm{~m}, \rho=10.5 \mathrm{Mg} / \mathrm{m}^{3}, \beta=$ 0.85 and the values of $H_{00}, Q^{\prime}$ and $W$ obtained in the experiments.

As the results of the trial and error calculation, it has been found that the use of $k_{\mathrm{sp}}=$ $108 \mathrm{MN} / \mathrm{m}$ and the values of $m(-)$ and $A$ $\left[(\mathrm{MPa})^{m} \cdot \mathrm{s}\right]^{-1}$ expressed by eq. (11) brings a good agreement between the calculated and the observed roll separating forces, as shown in Fig. 8.

$$
\log A=4.215-0.961 \cdot m \text {. }
$$

The calculated values of $2 H_{0}, x_{2}$ and $x_{1}$ depend on $m$ for $m \lesssim 3$, but independent of $m$ for $m \gtrsim 5$. Thus, for the sake of convenience, $m=6$ and $A=0.028\left[(\mathrm{MPa})^{m}\right.$. $\mathrm{s}]^{-1}$ were used in the following calculations. Originally the values of $m$ and $A$ should be determined on the basis of the deformation 
tests at high temperatures. Regarding the stress exponent $m$, for example, the value has been reported to be $2-7.1^{(7)}$ for $\mathrm{Pb}-\mathrm{Sn}$ and 3.5$5.2^{(8)}$ for A1-Si eutectic alloys. However, the value of $m$ for $\mathrm{Pb}-\mathrm{Sb}$ eutectic alloy used in this study has not been presented hitherto.

The comparisons between the calculated and the observed roll separating forces are shown in Figs. 8-10. The agreement is fairly good also in Figs. 9 and 10. It is understood that the theoretical prediction of roll separating force is possible for the other operational conditions in Figs. 9 and 10, if the values of $m$ and $A$ which satisfy the observed results in Fig. 8 are used.

Figure 12 shows the effects of roll rotation speed $\left(\omega_{0}\right)$ on the roll gap during rolling $\left(2 H_{0}\right)$, the end point of solidification $\left(-x_{2}\right)$ and the outlet of ribbon $\left(x_{1}\right)$. It is seen that with decreasing $\omega_{0}$ the end point of solidification moves upwards and the outlet of ribbon downwards. The reduction ratio in solidified ribbon thickness defined by $\left(H_{2}-H_{1}\right) / H_{2}$, where $H_{2}$ is the half ribbon thickness at the end point of
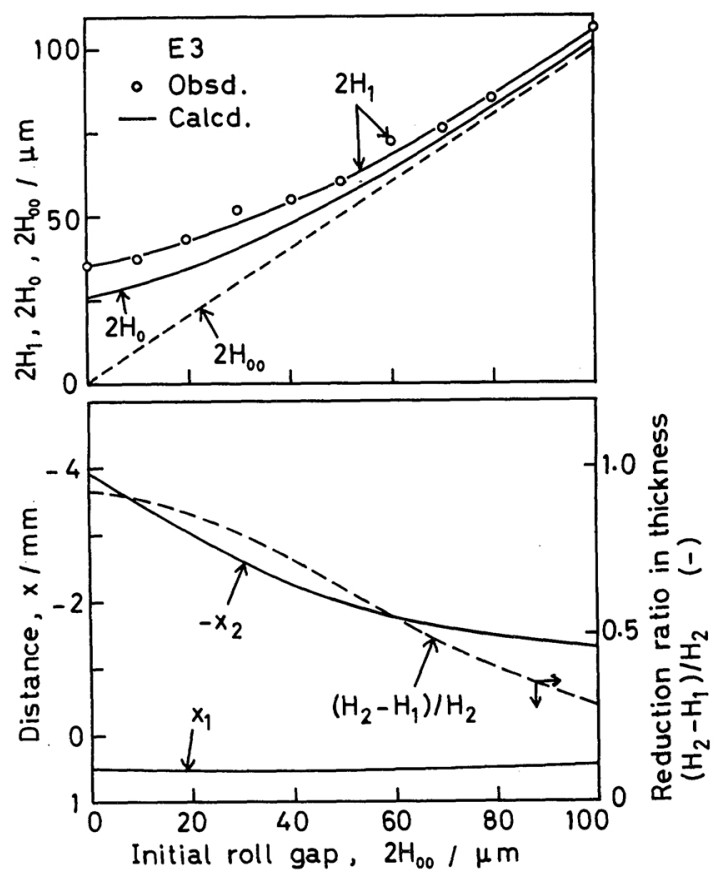

Fig. 12 Positions of outlet $\left(x_{1}\right)$ and end of solidification $\left(-x_{2}\right)$, reduction ratio in thickness of solidified metal, enlarged roll gap $\left(2 \mathrm{H}_{0}\right)$ and ribbon thickness $\left(2 \mathrm{H}_{1}\right)$ estimated for various roll rotation speed. ( $2 H_{00}$ : initial roll gap)
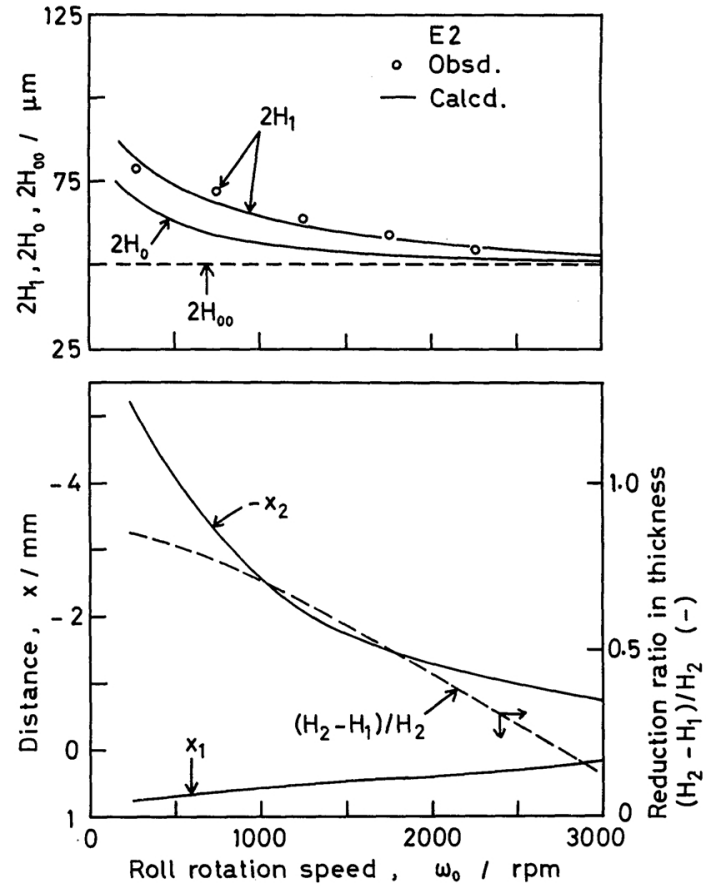

Fig. 13 Effects of initial roll gap on positions of outlet $\left(x_{1}\right)$, end of solidification $\left(-x_{2}\right)$, reduction ratio in thickness of solidified metal, enlarged roll gap $\left(2 \mathrm{H}_{0}\right)$ and ribbon thickness $\left(2 \mathrm{H}_{1}\right)$.

solidification, is also shown in Fig. 12 so as to increase with decreasing $\omega_{0}$. This makes the roll separating force increase with it, as shown in Fig. 8. Consequently the roll gap is enlarged and the ribbon thickness becomes larger with decreasing $\omega_{0}$.

The effects of initial roll gap on the various process variables are shown in Fig. 13. It is seen that the decrease in initial roll gap makes the end point of solidification move upwards and causes both the increase in roll separating force and the enlargement of roll gap. Thus, the effect of initial roll gap on the ribbon thickness can be explained through the change in reduction ratio of solidified metal and the enlargement of roll gap due to the rolling load.

Regarding the effects of melt flow rate, it has been found from the numerical calculations that under the conditions of the experiments E4 and E5 the outlet of ribbon is kept nearly constant, while the end point of solidification moves slightly upwards with the increase in melt flow rate. 


\section{Conclusion}

Characteristics of the rolling in the twin-roll rapid solidification process was investigated through the experiments using a $\mathrm{Pb}-\mathrm{Sb}$ eutectic alloy and the theoretical analysis on the deformation flow of the ribbon solidified during the rolling. Results obtained are as follows:

(1) The thickness of rapidly solidified ribbon decreases with increasing roll rotation speed and with decreasing initial roll gap and melt flow rate. The width increases with decreasing roll rotation speed and initial roll gap and with increasing melt flow rate. The crosssectional area of ribbon is proportional to the ratio of the melt flow rate to the roll rotation speed, but independent of the initial roll gap.

(2) The rolling speed of ribbon rapidly solidified in the roll gap is proportional exclusively to the roll rotation speed. The ribbon length per unit mass is in proportion to the ratio of the roll rotation speed to the melt flow rate. The rolling speed was found to be about $15 \%$ smaller than the roll surface velocity under unloading, mainly due to the slip between the solidified ribbon and the roll surfaces.

(3) The observed dependence of the ribbon thickness of the key process parameters has been quantitatively explained by the presented rolling theory. It has been found that the end point of solidification moves upwards in the roll gap with decreasing roll rotation speed and initial roll gap. As the result, the reduction ratio in thickness of solidified ribbon, the roll separating force and the enlargement of roll gap increase. The estimated roll separating force has been confirmed to agree well with the observed value.

\section{REFERENCES}

(1) K. Ohmori, K. Arai and N. Tsuya: Appl. Phys., 21 (1980), 335.

(2) K. Arai, N. Tsuya, K. Ohmori, H. Shimanaka and T. Miyazaki: J. Mag. Mag. Mater., 15-18 (1980), 1425.

(3) K. Inomata, S. Shimanuki and M. Hasegawa: Japan J. Appl. Phys., 19 (1980), L625.

(4) T. Sato, T. Kan, Y. Ito and H. Shimanaka: Collected Abstracts of the 1980 Spring Meeting of Japan Inst. Metals, p. 229.

(5) J. Ishihara and I. Ikuta: J. Japan Inst. Metals, 46 (1982), 94 (in Japanese).

(6) K. Miyazawa and J. Szekely: Met. Trans., 12A (1981), 1047.

(7) S. T. Lam, A. Arieli and A. K. Mukherjee: Mater. Sci. Eng., 40 (1979), 73.

(8) P. Delobelle, A. Mermet and C. Oytana: Mem. Sci. Rev. Metall., 72 (1975), 329. 